\title{
(2) OPEN ACCESS \\ How can existential or spiritual strengths be fostered in palliative care? An interpretative synthesis of recent literature
}

\author{
Marc Haufe $\left(\mathbb{0},{ }^{1}\right.$ Carlo Leget, ${ }^{1}$ Marieke Potma, ${ }^{1}$ Saskia Teunissen ${ }^{2}$
}

${ }^{1}$ Department of Care Ethics, University of Humanistic Studies, Utrecht, The Netherlands ${ }^{2}$ Department of General Practice, Center of Expertise Palliative Care Utrecht, Julius Center for Healthcare Sciences and Primary Care, Universitair Medisch Centrum Utrecht, Utrecht, The Netherlands

\section{Correspondence to} Marc Haufe, Care ethics, Universiteit voor Humanistiek, Utrecht, The Netherlands: M.Haufe@uvh.nl

Received 29 April 2020 Revised 21 July 2020 Accepted 24 August 2020

\section{Check for updates}

(C) Author(s) (or their employer(s)) 2020. Re-use permitted under CC BY-NC. No commercial re-use. See rights and permissions. Published by BMJ.

\begin{tabular}{|l|}
\hline To cite: Haufe M, Leget C, \\
Potma $\mathrm{M}$, et al. BMJ \\
Supportive \& Palliative \\
Care Epub ahead of \\
print: [please include Day \\
Month Year]. doi:10.1136/ \\
bmjspcare-2020-002379 \\
\hline
\end{tabular}

\section{ABSTRACT}

Background Patients receiving palliative care may benefit greatly when their existential or spiritual strengths are fostered. To date however, there has not been a comprehensive literature review of patient and care professional approaches that are available.

Aims To describe and synthesise existential or spiritual strength-based approaches within the context of palliative care.

Methods Literature search of 2436 articles between January 1999 and March 2019 in Scopus, Web of Science, CINAHL and PsycINFO. Articles were included if they deal with a palliative care situation, focus on the patient, specific existential/spiritual strength, discernible strength approach and an analysis of the workings of that approach. The interpretative synthesis consisted of a thematic analysis of the included articles and an integration of themes.

Results In the 14 included articles, 5 different strengths were found to be fostered by 16 approaches: (1) Meaning was fostered by: maintaining normalcy, experiencing sanctuaries, reassessing importance and reconstructing positive self; (2) Connection by: opening up, giving/receiving care and envisioning continuation; (3) Agency by: maintaining control, refocusing goals and continuous adaptation; (4) Hope through: setting special targets, imagining alternate outcomes, building a collection and extending wishes; (5) Faith through: living the tradition and relating to a benevolent force. Strengths and approaches are visualised in an overarching analytical framework: 'the Propeller'.

Conclusions The constructed Propeller framework can be used to become aware of, apply and further develop approaches to foster existential or spiritual strengths among patients receiving palliative care.

\section{BACKGROUND}

Spiritual well-being has repeatedly been found to be associated with positive psychosocial functioning and overall quality of life in patients receiving palliative care. ${ }^{12}$ Spiritual support from a patient's medical team or chaplain seems to contribute to this. ${ }^{34}$ Many patients look to their doctors and nurses to help them make sense of their spiritual issues. ${ }^{5-7}$ But many doctors and nurses do not feel comfortable or equipped to do so. ${ }^{8-11}$ This, in part, is because palliative care has predominantly focused on the prevention and relief of physical and psychosocial problems to improve quality of life. ${ }^{12-14}$

Spiritual palliative care is often understood and administered as consisting of assessments and interventions to directly avoid or tackle a spiritual crisis. $^{15} \mathrm{~A}$ different way to understand spiritual palliative care, however, is as an approach that can contribute to quality of life by identifying and supporting existential or spiritual strengths of patients. ${ }^{16-18}$ Such an approach may serve as a buffer against negative feelings, and can help pave the way towards inner peace and transcendence. ${ }^{19}$

This strengths-based perspective, stemming from the field of social work, and taking hold in nursing, chaplaincy, counselling and psychotherapy, ${ }^{20-24}$ has slowly become more manifest in spiritual or existential palliative approaches. ${ }^{25} 26$ Familiarity with such approaches could help care professionals, especially those not specialised in spiritual care, to provide more and more specific day-to-day spiritual support to patients.

To the best of our knowledge this is the first thematic review of existential or spiritual strengths-based approaches. 
The research question was: what is known about how patients receiving palliative care can foster their existential or spiritual strengths? The goals of this study were to classify approaches that can be seen as existential or spiritual strength based and synthesise these in an overarching framework.

\section{METHODS}

\section{Study design and working definition}

For our review we conducted an interpretative synthesis. An interpretative synthesis goes beyond a summary of studies by reanalysing and combining findings from various studies into a whole. ${ }^{27}$ This whole offers a conceptual framework that provides added value through new insight into the subject of study. As the primary focus our interpretive synthesis was to map a first overview of empirically grounded strength fostering approaches in its manifoldness, no additional quality assessment or risk of assessment bias was conducted.

At the start of our interpretative synthesis process, we used as a working definition of strengths the definition by Gottlieb, ${ }^{21}$ from the innovative field of strengths-based nursing care:

\begin{abstract}
Strengths are a person or family's special and unique qualities and resources that define their personhood. Strengths are needed to meet goals, develop health, meet illness challenges, facilitate and promote healing by restoring wholeness, and assist the person to get the most out of living. Strengths are a person's capabilities, and they come in many forms, including assets, capacities, competencies, resources, skills, talents, and gifts.
\end{abstract}

This definition was deemed suitably complete regarding the understanding of strengths and strengths-based approaches to start a preliminary investigation with.

\section{Preliminary investigation and search strategy}

To gain a first understanding of dominant concepts and terms associated with existential and spiritual strengths care approaches, a preliminary investigation was conducted in Google Scholar by the researcher $(\mathrm{MH})$. This investigation provided a successive overview of the field through: (1) A typology of how patient strengths are understood in the palliative care literature, (2) A typology of to what spiritual or existential ends these strengths are deployed, (3) A typology of approaches and methods associated with these ends, and (4) A typology of working ingredients mentioned in the approaches and methods found. This overview was then discussed between the researcher $(\mathrm{MH})$ and senior researcher (CL) in order to reach a joint understanding of key concepts and help determine search strategy aspects. It was noted that fostering existential and spiritual strengths helped patients feel more positive and resilient through concepts like meaning and purpose, hope, connection and dignity. With regard to the fostering approaches, it became clear that these

\begin{tabular}{|c|c|}
\hline $\begin{array}{l}\text { Search } \\
\text { category }\end{array}$ & Corresponding search string \\
\hline Care situation & $\begin{array}{l}\text { "end of life" OR "palliative" OR "terminal" OR "life } \\
\text { threatening illness" }\end{array}$ \\
\hline Main theme & $\begin{array}{l}\text { strength* OR resource* OR transcend }^{*} \text { OR meaning* } \\
\text { OR purpose* OR hope* OR connect* OR resilien* OR } \\
\text { coping OR healing OR dignity }\end{array}$ \\
\hline $\begin{array}{l}\text { Relevant } \\
\text { dimensions of } \\
\text { main theme }\end{array}$ & spirit* $^{*}$ R existen* OR religio* OR psycholog* \\
\hline Approach type & 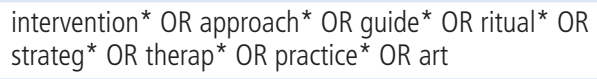 \\
\hline $\begin{array}{l}\text { Accent on } \\
\text { identifying }\end{array}$ & identif* $O R$ find $^{*} O R$ acces* $O R$ asses ${ }^{*}$ \\
\hline $\begin{array}{l}\text { Accent on } \\
\text { supporting }\end{array}$ & support ${ }^{*}$ OR facilitat* OR foster* OR utili* OR bolster* \\
\hline
\end{tabular}

had both identifying and supporting mechanisms. With regard to our working definition it also became clear that existential or spiritual strengths were less about unique characteristics of personhood (such as talents and gifts), and more about accessing and experiencing a strongly sustaining feeling of transcendence. These terms and conceptual enrichments provided a more precise frame of inquiry and were used as input for a first search string that was built with the help of an experienced information specialist.

This search string was then further honed within the Scopus database as it was deemed most promising for a review question with existential, spiritual, religious and psychological aspects. The search was further refined to include only empirical, peer-reviewed articles of the last 20 years (dating back from 21 February 2019), so as to avoid opinion pieces and include the most recent scientific paradigms. Furthermore, only English articles were included. Following the advice of the information specialist, the final search string was then used to search Scopus and the Web of Science, PsycINFO and Cumulative Index to Nursing and Allied Health Literature databases, to ensure the inclusion of more relevant articles. See table 1.

\section{Inclusion criteria and study selection}

Based on discussions and key articles found within the preliminary search, the researcher $(\mathrm{MH})$ and senior researcher (CL) determined the criteria for articles to be included in the search. Articles were included only if they fulfilled all five following criteria: (1) A focus on palliative care, (2) A focus on the patient, (3) Naming patients' existential, spiritual, religious and or psychological sources of strength, (4) Naming approaches to foster these strengths, and (5) Containing empirical grounding of how these fostering approaches worked.

The researcher $(\mathrm{MH})$ made the first selection based on title. Researcher $(\mathrm{MH})$ and senior researcher (CL) independently then scored the abstracts of selected articles as suitable or unsuitable for inclusion. Abstracts 


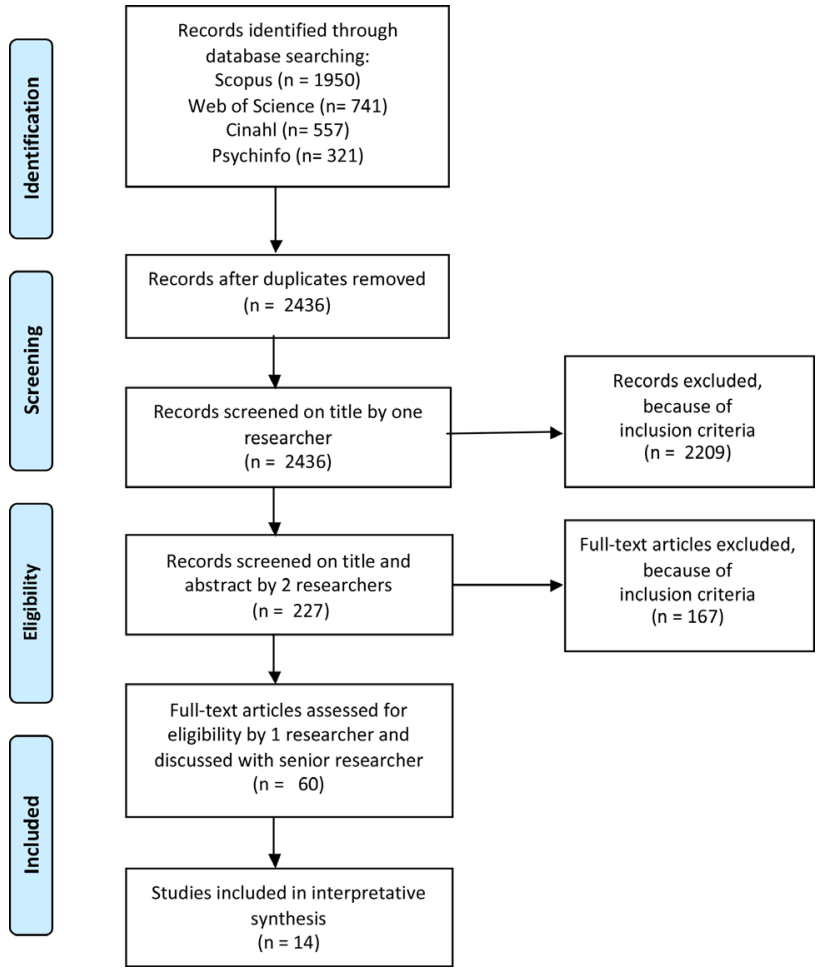

Figure 1 Flow diagram of the study selection procedure.

that were agreed on as suitable were included. For abstracts where there was disagreement of suitability, researchers discussed their differing selections until agreement was reached on suitability for inclusion as full-text article. The researcher (MH) then selected the final batch of articles to be included and discussed the eligibility of these with the senior researcher (CL) until they reached agreement on eligibility. Figure 1 describes the results of the data selection procedure.

\section{Analysis}

Included articles were summarised for analysis purposes listing the authors, existential or spiritual strengths named, a description of the strength fostering approaches linked to the named strengths, and the guiding or working principles of those approaches. The descriptions of the strength fostering approaches and their working principles were grouped according to the corresponding strengths and each group was then subjected to thematic analysis by the researcher $(\mathrm{MH}){ }^{28}$ From this grouping five types of existential or spiritual strengths emerged.

Thematic synthesis was done in order to identify and name overarching themes with regard to the found fostering approaches and their working principles. Sixteen such themes (approaches and corresponding working principles) were found. Named themes were compared with the source texts, to check alignment with the original descriptions within the articles. By contrasting the overarching themes per group with each other through constant comparison, a clearer understanding was also reached with regard to the defining characteristics of each strength. Following this analysis, the researcher $(\mathrm{MH})$ discussed the overarching approach themes with the senior researcher (CL) and a visualisation best encapsulating the results was conceptualised.

\section{RESULTS}

\section{Interpretive synthesis review}

Table 2 presents the characteristics of the 14 studies included. Overall, 909 patients participated in these studies in eight different countries. Most patients were English speaking with end-stage cancer researched in the USA. At least nine types of professional disciplines were involved. Seven of the included studies only explored the spontaneous existential or spiritual strength approaches of patients. ${ }^{29-35}$ Five dealt with more formal approaches of care professionals to help patients. ${ }^{36-40}$ Two studies contained elements of both, conducting an interview with patients as an existential or spiritual intervention, and exploring natural approaches in the analysis of given answers. ${ }^{41} 42$

Through thematic analysis, 16 existential and spiritual strength approaches emerged, grouped according to five main strengths: meaning, connection, agency, hope and faith. Certain papers contained multiple approaches related to various strengths (see main findings below). Ten papers contained approaches related to meaning, nine papers to agency, nine to hope and four to faith.

\section{Working definition}

Analysis also revealed that existential or spiritual strengths are thought of as deeply sustaining feelings that repeatedly give patients the experience of energy, certainty, clarity and guidance. Furthermore, it emerged that existential or spiritual strength fostering approaches often appear circular. That is, the strengths were found to be a source, vehicle and end result of the fostering, forming a virtuous cycle as opposed to a vicious cycle. The existential strength of meaning, for example, was seen to be fostered by making meaning, using previous meanings.

\section{Main findings}

Meaning

Being able to experience meaning as an existential or spiritual strength was found in a broad variety of the included studies. ${ }^{31} 323436-42$ In understanding and feeling what is truly significant to them, patients receiving palliative care were able to boost their wellbeing. Overall, four distinct approaches that foster this type of strengthening experience were found: maintaining a sense of normalcy, experiencing sanctuaries, reassessing what is most important and reconstructing an essentially positive self.

\section{Maintaining a sense of normalcy}

In studies that described the more or less spontaneous approaches by patients themselves, upholding meaning 


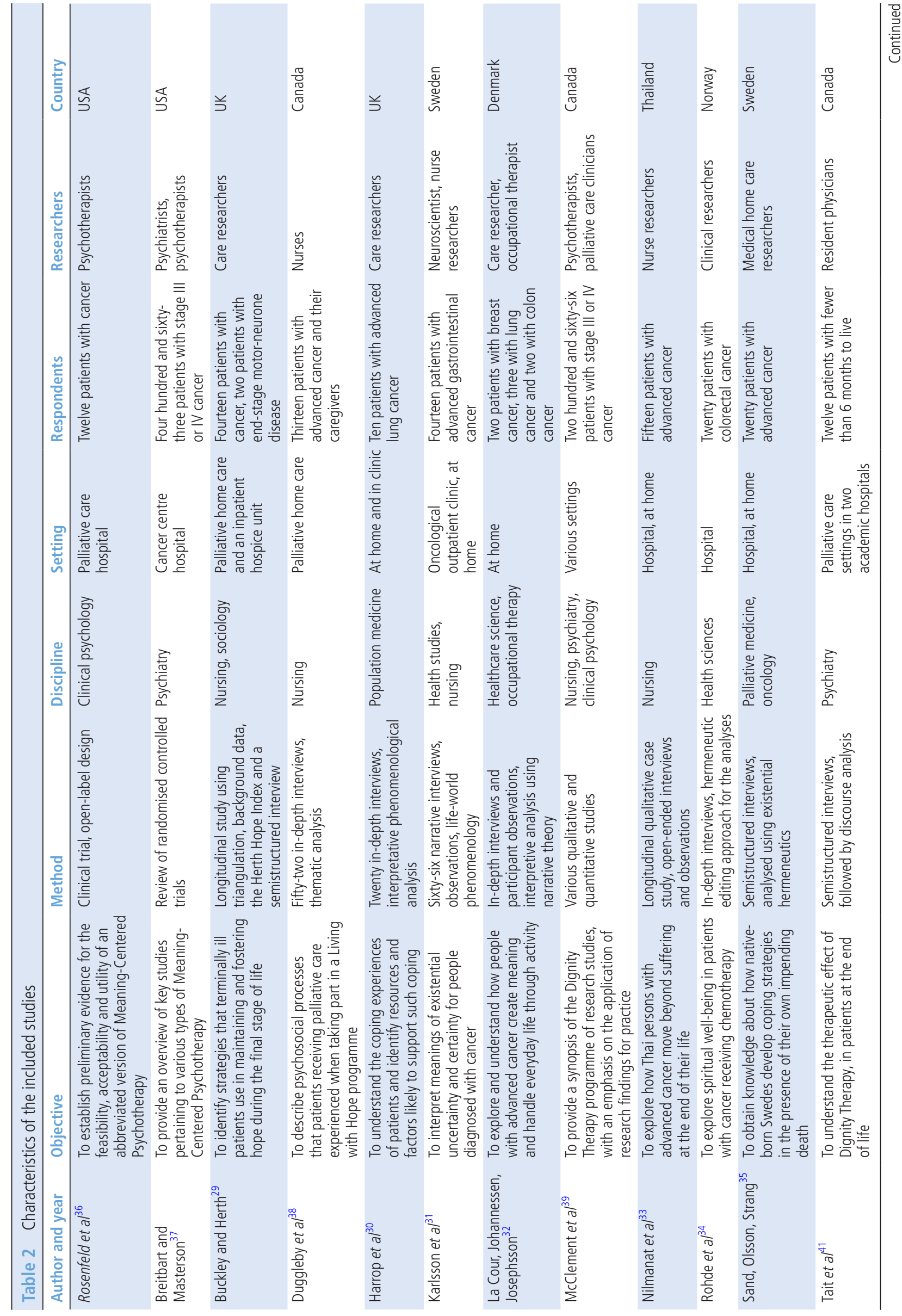


through maintaining a sense of normalcy stood out. ${ }^{32} 34$ Patients did so by continuing their valued daily routines as much as possible. For instance, they derived positive meaning from rituals such as having a start-up moment with a morning cup of coffee, still being able to walk the dog or go to a museum. By focusing on such activities and telling people about them, patients were able to find strength in the invigorating sense that previously valued life aspects still continued.

This approach was also found in studies concerning the professional therapeutic approach of Dignity Therapy. ${ }^{3941}$ By asking patients directly about their valued routines and activities and facilitating the continuation of these, care professionals strove to contribute to the maintenance of meaningful life aspects. Within Dignity Therapy, this continuation is furthermore extended to ascertain meaningful family or societal roles of patients, such as caregiver or advisor, and facilitate the continuation of such roles wherever possible.

\section{Experiencing sanctuaries}

Certain patients also found strength through experiencing sanctuaries. ${ }^{31} 32$ By turning away from the daily pressures and seeking refuge in special activities and places, patients were able to replenish themselves. Through these replenishing experiences in turn, such places and activities attained special meaning, as givers of existential/spiritual strength. Examples of sanctuaries included being in a specially decorated room that one had helped design, or being in a special place in nature, for instance through gardening.

\section{Reassessing what is most important}

Within the palliative context patients spontaneously also took the time to reflect on their own lives and take stock. ${ }^{31}$ By allowing themselves to think deeply and clearly about what has been most important to them in their life, they prioritised, aggregated and integrated a sense of existential or spiritual meaning. Through reassessing, patients gained a new perspective on life and with it a strong feeling of inner strength and a wish to focus only on what they deemed most important in the remaining time.

The facilitation of this kind of reflection is also at the heart of the professional care approach of MeaningCentered Therapy. ${ }^{36}{ }^{37}$ Within multiple therapy sessions, palliative care patients are invited to reflect on what has been, and is, important in their lives. Three main life aspects are introduced and explored: the attitudinal, mainly found in exploring how patients successfully overcame previous life challenges and limitations; the experiential, found in exploring experiences of love, beauty and joy/humour; and the creative, found in exploring how patients fulfilled important roles and worked to achieve important goals. Through such reflection, important aspects of patients' lives become activated as existential or 
spiritual strengths that can be drawn on to face current challenges and help shape ideas about what to do in the immediate future. Likewise, Dignity Therapy and a professional Life Review programme, ${ }^{40} 42$ contain meaning-activating questions such as: what are the most important roles you have played in life (family roles, vocational roles, community service roles, etc)?, what are your most important accomplishments? and what do you feel most proud of?

\section{Reconstructing an essentially positive self}

Reassessing what is most important is similar to, yet separate from, the spontaneous approach of reconstructing an essentially positive self. ${ }^{31} 42$ Through the reassessment of important roles and relations, attitudes intermingled with overcoming adversity, experiences of love and beauty, goals and accomplishments, patients can also create a new understanding of who they are. This reconstruction can give a heightened sense of personal growth and an experience of a positive identity as existential or spiritual strength.

Facilitation of this type of reconstructing could also be found in the professional approaches of legacy making. ${ }^{36-40}$ In such approaches, patients are asked to act on questions like; are there specific things that you would want your family to know about you, and are there particular things you would want them to remember? By stimulating patients to assemble an essentially positive 'about me' collection to pass on to significant others, for instance, in the form of a diary, booklet, collage or recording, care professionals seek to bolster an experience of positive personhood.

\section{Connection}

Feeling deeply connected with others also emerged as an important existential or spiritual strength. ${ }^{30} 31$ 34-40 It is in the real or imagined sharing of positive feeling that these patients felt energised. Three strength-based connection-building approaches were found: opening up to significant others, giving and receiving care and envisioning continuation across generations.

\section{Opening up to significant others}

Sharing worries was seen to be a way to deal with existential uncertainty. ${ }^{31}$ But there was another side to this sharing as well. Through opening up about their most cherished memories, emotions and beliefs, and sharing these with significant others, loved ones and caretakers, patients felt great strength in a bonding experience. $^{3435}$

This type of sharing is also facilitated within the care professional approach of Meaning-Centered Therapy and the PATS (Presence, Active Listening, Touch, Sacred Story) intervention. ${ }^{36} 3742$ Patients are stimulated to search for different types of meaning in their lives, and to share what they find with significant others. By encouraging patients to open up and share, be it in conversations, letter writing, or other means, meaning-centred therapists seek to stimulate the strength-giving aspects of relationships.

\section{Giving and receiving care}

Through the maintenance of certain familial and societal roles (a sense of normalcy), patients also sought to maintain the ways to care for and receive care from loved ones. ${ }^{30}$ By continuing care activities, for instance, with regard to children or grandchildren, they felt a vital connection in being able to provide, help and guide. Likewise, in being cared for, by loved ones and/ or care professionals, certain patients felt existential strength in being appreciated.

\section{Envisioning continuation across generations}

Some patients sought to bolster a sense of connection by becoming more conscious of their individual life in relation to the preceding and succeeding familial generations. $^{35}$ By taking the time to become more mindful of such a grand flow of interrelations and the importance of the continuing succession, certain patients found strength in feeling a part of a familial line.

Such envisioning is also facilitated by the legacy making aspects of various care professional approaches. $^{36} 373940$ Therein, a central question by care professionals is: what wisdoms, traditions or lessons learnt would you wish to impart to future generations? As patients think about what to pass on, a deeper feeling of continuance through the generations may emerge and invigorate.

\section{Agency}

Analysis of the included studies showed that a sense of agency could be an existential or spiritual strength for patients. ${ }^{29-32} 3436373942$ In (still) experiencing a capacity to act, to be able to do and affect something, these patients receiving palliative care became infused with vigour. Three agency-building approaches were found to be of key importance in this regard: maintaining a sense of control, refocusing goals and continuous adaption.

\section{Maintaining a sense of control}

Closely akin to the meaning approach of maintaining normalcy, is the agency bolstering one of maintaining a sense of control. By being able to initiate cherished activities, such as staying involved in planning things and caring for others, patients spontaneously also sought to retain a sense of control. For some, this control stimulated an energising feeling that they were still in charge of certain things in their lives. ${ }^{31} 3234$

The professional approach of Dignity Therapy also was found to enhance a sense of control ${ }^{39}$ in that it stimulates continuation of cherished activities and roles. In addition, because Dignity Therapy seeks to continuously provide a sense of choice, for instance, regarding care decisions and planning, it also can 
enhance experienced control and responsibility. Lastly, Meaning-Centered Therapy and the PATS interview intervention, ${ }^{36} 37{ }^{42}$ through exploring memories of overcoming adversity, also give patients a sense of control, although based on past events.

\section{Refocusing goals}

Some patients who were able to support agency themselves, also sought to refocus their goals, so that they could continue to attain them. First, they sought to foreground short-term goals and let go of long-term ones, allowing them to focus on what was achievable now. ${ }^{34}$ Second, fuelled by the realisation that living now was the most important thing, patients reprioritised their goals. They realised that certain activities, such as taking a trip, making a phone call or a having family get-together, should not be postponed any longer. ${ }^{31}$ Third, patients refocused goals by honing in on more modest or subtle positive milestones, such as striving to still dress oneself everyday. ${ }^{29}$ Through this refocusing on the immediate, timely and achievable, a sense of agency was maintained or rekindled.

This refocusing of goals is also aided in aspects of Dignity Therapy. ${ }^{39}$ By talking to patients about and encouraging the redefining of what is still possible, care professionals facilitate the assessment of how a sense of agency can be found.

\section{Continuous adaptation}

For some patients, agency was also found in continuously adapting, finding new ways to keep reaching desired goals. ${ }^{3032}$ They did this through finding substitutions for cherished activities that were no longer possible or by continuously checking if activities that were not possible before became possible again. By seeking other means to the same end, for instance, finding ways to share a family moment other than a family dinner because of difficulty in eating, patients creatively found ways to adapt. In addition, by continuously checking if certain activities became possible again, even temporarily, they found opportunities to pursue these once more.

\section{Hope}

Having hope was also found to be an existential or spiritual strength for patients in the included studies. ${ }^{29313335-3941}$ Through having a positive perspective on the possibilities of the future, patients could still feel the push and pull of optimism. Thematic analysis of the studies revealed four ways by which hope could be supported or enhanced: setting special targets, imagining alternate outcomes, building a collection and extending wishes.

\section{Setting special targets}

Very much akin to the previously mentioned agencybuilding approach of refocusing goals, is the subset approach of setting special targets. ${ }^{29} 31$ By setting overriding objectives of key significance, such as achieving final personal growth or spending time with a son from abroad one last time, some patients also cultivated prospective ideas that could uplift them.

In part this process is also facilitated within Dignity Therapy and Meaning-Centered Therapy. ${ }^{36} 3739$ In helping patients to prioritise their expectations about the possible future, such special targets can also be set.

\section{Imagining alternate outcomes}

In two studies it was found that patients also used their imagination or a type of magical thinking to engender a feeling of hope..$^{33} 35$ By fantasising about the possibility of a miracle cure or imagining themselves still being a (spiritual) presence in the lives of loved ones, they entertained alternative strength-giving scenarios.

\section{Building a collection}

In one study, focusing on the care professional Living with Hope programme, ${ }^{38}$ patients were encouraged to collect symbols that gave them hope. This was done in order to more fully help form and sustain hope as an existential or spiritual strength. Patients' hope collections included poems, writings, pictures, photographs and music. Focusing on these items intermittently helped some to raise their spirits.

\section{Extending wishes}

The hope-building exercise of extending wishes was found in multiple care professional approaches. ${ }^{36-39} \mathrm{By}$ stimulating patients to think about what they wished for loved ones in the future and extend it, for instance, through conversations, letter writing and legacy documents, care professionals sought to affix attention on a positive future. Within the legacy making activity, ${ }^{363739}$ this extending of wishes about the future was found to be closely aligned with the sharing of valuable lessons learnt that patients wished to impart.

Faith

Lastly, faith was also found to be an existential or spiritual strength in certain studies. ${ }^{29} 313334$ Through placing trust in the supernatural and honouring it, some patients receiving palliative care experienced the grace of the divine. Analysis of these studies revealed two strength-building approaches: living the tradition and relating to a benevolent force.

Living the tradition

Within the palliative phase, some patients sought to enhance their knowledge of, and/or adherence to, spiritual or religious traditions. ${ }^{29} 3334$ By strongly (re) connecting to basic Christian, Buddhist or Islamic tenets, such as the importance of connecting with family and the community, the wheel of cause and effect or the unconditional surrender to the will of God, they found basic beliefs that could give strength. Adhering to doctrinal activities such as prayer, 
meditation or making merits by giving alms, honoured these beliefs and made them practical, providing invigorating guidance.

\section{Relating to a benevolent force}

Though relating to God as a benevolent force could be a part of living the tradition, ${ }^{33}$ relating to a benevolent force outside of tradition was also found to be an important strength-building approach for some patients. These patients sought to feel and relate to a benevolent force as a friend or partner, being there for them and guiding the process of care. ${ }^{34}$ Some also related to this force of good as a current flowing through the care professional. ${ }^{29}$

\section{Synthesis}

Each of the aforementioned approaches can be grouped according to an overriding working principle of that strength. Meaning is about finding significance in various life aspects. Connection concerns sharing positive feelings in various ways. Agency is about experiencing the capacity to act, to do and affect. Hope pertains to having an optimistic future perspective. And faith consists of relying on the supernatural.

Each strength-giving approach seems to build on kernels already present, stimulating in patients more fully a deep feeling that lifts, invigorates and guides. In this manner the workings of the found existential or spiritual strengths approaches seem to be somewhat circular. For instance, kernels of hope are located and stimulated through a hopeful exercise, stimulating a sustaining feeling of hope.

At the same time, a fair amount of correspondence seems to bind approaches together across strength groups. Ways that engender hope for instance, such as setting special targets, are much aligned with the refocusing goals approach that instigate a sense of agency. Likewise, maintaining normalcy can allow for the continuation of meaningfulness in patients' lives while at the same time, through maintaining important roles, facilitate a sense of connection.

Based on such mechanisms, similarities and synchronisations, the approach groups discussed can be visualised as separate, yet interlinked, strengthening each other. Much like the blades of a propeller, as can be seen in figure 2.

\section{DISCUSSION}

\section{Main findings}

Our review findings suggest that within the domain of palliative care, at least 16 existential approaches foster five existential or spiritual strengths. Maintaining a sense of normalcy and finding sanctuaries, reassessing what is important in life and reconstructing an essentially positive self were found to bolster a sense of meaning for patients. Opening up to significant others, giving and receiving care and envisioning continuation across generations, was

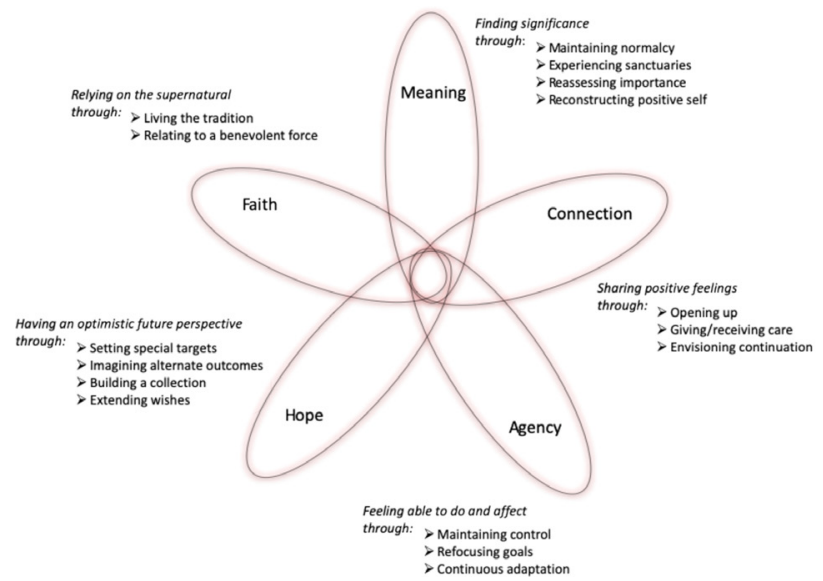

Figure 2 The propeller; a model of existential/spiritual strength approaches.

seen to foster a deep sense of connection. Being able to maintain control and also the refocusing of goals and an approach of continuous adaptation reinforced the experience of existential agency. Setting special targets, imagining alternate outcomes, building a collection and extending wishes kindled feelings of strength-giving hope. And lastly, the approaches of living the tradition and relating to a benevolent force strengthened faith.

Most approaches were found to be present in spontaneous, patient-driven processes, as well as in more formal care-driven interventions and programmes. Care professional approaches were found to explicitly encourage and support all of the patient-driven approaches mentioned above, except for experiencing sanctuaries, imagining alternate outcomes and relating to a benevolent force. Conversely, only two sole care professional approaches were found in this review: extending wishes and building a collection. ${ }^{43-46}$ In this regard it can be said that, when working to enhance sources of existential and spiritual strengths, care professionals seem to closely follow what patients spontaneously seek to do.

With regard to ways to understand existential or spiritual strengths, our frame of reference evolved from strengths as unique qualities such as traits and talents that define a person's personhood, ${ }^{21}$ to strengths as deeply sustaining feelings that repeatedly give patients the experience of energy, certainty, clarity and guidance. As such, existential or spiritual strengths emerge out of creative relationships between that individual and their environment. Within that creative relationship, strength fostering can be seen as a virtuous cycle: taking existing elements of the strength (such as symbols of hope) and rearranging or adding on to them in such a way that a new sustaining feeling arises. A person might do this in a solitary manner or together with others. 


\section{Strengths and limitations}

In bringing together these approaches as they relate to specific existential or spiritual strengths this review offers new insight. To our knowledge, this is the first study that has reviewed the palliative care literature from a broad existential or spiritual strength-based approach perspective. There are a number of reviews on particular strengths, such as meaning or hope, but these usually do not include other approaches to foster these strengths. Rather, they have sought to understand and integrate the development of meaning or hope as a concept, ${ }^{478}$ or illuminate care professional perspectives on patients. ${ }^{43}$

Certain reviews concerning Dignity Therapy and life review do cover some of the bases mentioned in our review, ${ }^{44} 45$ for instance, with regard to finding strength in a diverse array of meanings, but more from an evaluative perspective of outcomes. They do not strive to explain the working principles that specifically foster existential or spiritual strength.

One review, by Guerrero-Torrelles et al, ${ }^{46}$ does try and explain how interventions can promote positive meaning by outlining a few overriding principles. But this review too, does not make clear how each approach contributes to the bolstering of an existential or spiritual strength. Our review does make these types of connections clear and does so for a wider array of resources. In this way our 'Propeller' can contribute to a greater awareness and understanding of how existential or spiritual strength fostering within the palliative setting works and can be facilitated.

Apart from these strengths, this review has its limitations. First, a strict set of selection criteria was maintained for this review. For instance, articles were only included if they explicitly dealt with a discernible existential or spiritual strength-based approach and a reflection on the specific workings of steps or aspects of that approach. This combination has excluded articles that offer cursory pieces of the strength-based approach puzzle. In the aforementioned review on meaning by Guerrero-Torrelles et al for instance, a gratitude approach is named, but its workings are not explained, and has therefore not been included.

Second, an emphasis in this review on empirical material has also excluded practices that could be of interest but have not themselves been subjects of empirical research. This has, for example, led to the exclusion of interesting existential strength-related questions which have not been examined in their use, such as: 'do the important people in your life know what they mean to you?' contained in block, ${ }^{49}$ or 'what is there in your life that gives you internal support?', within the HOPE assessment approach. ${ }^{19}$ Because of these limitations, our review can best be viewed as a starting point, providing a framework on which to build and to refine.

Lastly, within the parameters of our selection criteria we have found only a few articles that were suitable for inclusion. Because the 'Propeller' is based on a modest amount of articles, it can only be seen as a first step in charting a new research theme. The dependability and transferability of the themes found need to be further tested in research and practice.

\section{Clinical implications}

The proposed 'Propeller' framework can help professionals working in palliative care, especially those not specialised in spiritual care, in a number of ways. First, it stimulates awareness that there are specific approaches that can lead to patient experiences of existential or spiritual strength, and that these ways are important from a distress-reducing perspective, and from a viewpoint of (final) human flourishing. This awareness can also be supported by the insight that the existential or spiritual is often found in everyday, simple things, and is mostly not situated in an otherworldly dimension out there, but in an essential dimension right here.

Second, through awareness of the found approaches, care professionals can learn to align and coordinate their care more to find and foster existential or spiritual strengths. This can take the form of better facilitating what is already happening, of providing guidance to patients who are trying to find their way or of stimulating patients' awareness of another, possibly more positive, side.

Third, the propeller model can offer care professionals a starting point to become aware of other ways to find and foster existential or spiritual strengths. The five strengths and 16 approaches identified are only a preliminary configuration, to which existing, nonscientific but pragmatic approaches, for instance, of experienced nurses in palliative care, can be added.

With all the above applications, however, the framework must not be seen as a way to simply assess a patient's strengths. Professionals should be mindful of the finding that existential or spiritual strengths emerge out of and build on creative relationships between that individual and his or her environment. The ways in which these creative relationships can best be fostered are, in the end, unique for each individual.

\section{Future research}

In light of the above, three avenues for future research can be stipulated. First, different ways to thoroughly examine the existing literature with regard to existential or spiritual strength-fostering approaches should be carried out to gain a more complete scientific picture of this important, yet underdeveloped, palliative care domain. By providing different scientific review windows on this subject, a debate can be stimulated as to how, existential or spiritual strengthfostering palliative care should be understood and carried out. Based on this review, the scientific debate seems to be largely missing, even though quite a few scientists have emphasised the importance of this type of care. $^{116171925}$ 
Second, and for the same reasons, more research needs to be conducted to understand and evaluate just how a diverse array of patients' and care professionals' strength-fostering approaches work. Taking the characteristics of the patient population covered by this review into consideration, it would be important to extend research to other countries and cultural groups.

Third and lastly, more research needs to be done that engages and incorporates practical knowledge of palliative care professionals, in order to scientifically unearth and test existing strength-fostering wisdoms in the field. The practice of participatory action research, ${ }^{50}$ with its emphasis on co-creation within a cyclical research design of plan, try, evaluate and adjust, seems to be particularly well suited in this regard.

\section{CONCLUSION}

In conclusion, the researchers are hopeful that the proposed 'Propeller' framework may power up scientific debate on the importance of existential or spiritual strengths approaches and stimulate greater awareness among palliative care professionals of how to support patients receiving palliative care.

Funding This work was supported by the Netherlands Organisation for Health Research and Development (ZonMW), grant number: 84400150, 2017.

Competing interests None declared.

Patient consent for publication Not required.

Provenance and peer review Not commissioned; externally peer reviewed.

Open access This is an open access article distributed in accordance with the Creative Commons Attribution Non Commercial (CC BY-NC 4.0) license, which permits others to distribute, remix, adapt, build upon this work noncommercially, and license their derivative works on different terms, provided the original work is properly cited, appropriate credit is given, any changes made indicated, and the use is noncommercial. See: http://creativecommons.org/licenses/by-nc/4. $0 /$.

\section{ORCID iD}

Marc Haufe http://orcid.org/0000-0002-4944-9592

\section{REFERENCES}

1 Puchalski CM. Spirituality in the cancer trajectory. Ann Oncol 2012;23 Suppl 3:iii49-55.

2 Visser A, Garssen B, Vingerhoets A. Spirituality and well-being in cancer patients : a review. Psychooncology 2010;572:565-72.

3 Balboni TA, Paulk ME, Balboni MJ, et al. Provision of spiritual care to patients with advanced cancer: associations with medical care and quality of life near death. J Clin Oncol 2010;28:445-52.

4 Delgado-Guay MO. Spirituality and religiosity in supportive and palliative care. Curr Opin Support Palliat Care 2014;8:308-13.

5 El Nawawi NM, Balboni MJ, Balboni TA. Palliative care and spiritual care: the crucial role of spiritual care in the care of patients with advanced illness. Curr Opin Support Palliat Care 2012;6:269-74.

6 Lundmark M. Attitudes to spiritual care among nursing staff in a Swedish oncology clinic. J Clin Nurs 2006;15:863-74.
7 Ehman JW, Ott BB, Short TH, et al. Do patients want physicians to inquire about their spiritual or religious beliefs if they become gravely ill? Arch Intern Med 1999;159:1803-6.

8 Curlin FA, Lawrence RE, Odell S, et al. Religion, spirituality, and medicine: psychiatrists' and other physicians' differing observations, interpretations, and clinical approaches. Am J Psychiatry 2007;164:1825-31.

9 Phelps AC, Lauderdale KE, Alcorn S, et al. Addressing spirituality within the care of patients at the end of life: perspectives of patients with advanced cancer, oncologists, and oncology nurses. J Clin Oncol 2012;30:2538-44.

10 Ramondetta LM, Sun C, Surbone A, et al. Surprising results regarding MASCC members' beliefs about spiritual care. Support Care Cancer 2013;21:2991-8.

11 Ronaldson S, Hayes L, Aggar C, et al. Spirituality and spiritual caring: nurses' perspectives and practice in palliative and acute care environments. J Clin Nurs 2012;21:2126-35.

12 Gardiner C, Gott M, Ingleton C, et al. Extent of palliative care need in the acute hospital setting: a survey of two acute hospitals in the UK. Palliat Med 2013;27:76-83.

13 Rome RB, Luminais HH, Bourgeois DA, et al. The role of palliative care at the end of life. Ochsner J 2011;11:348-52.

14 Gómez-Batiste X, Martínez-Muñoz M, Blay C, et al. Identifying needs and improving palliative care of chronically ill patients: a community-oriented, population-based, public-health approach. Curr Opin Support Palliat Care 2012;6:371-8.

15 Best M, Aldridge L, Butow P, et al. Assessment of spiritual suffering in the cancer context: a systematic literature review. Palliat Support Care 2015;13:1335-61.

16 Balboni TA, Fitchett G, Handzo GF, et al. State of the science of spirituality and palliative care research Part II: screening, assessment, and interventions. J Pain Symptom Manage 2017;54:441-53.

17 Ellis J, Lloyd-Williams M. Palliative care. In: Cobb MR, Puchalski CM, Rumbold B, eds. Oxford Tex. New York: Oxford University Press, 2012: 1-19.

18 Puchalski CM, Lunsford B, Harris MH, et al. Interdisciplinary spiritual care for seriously ill and dying patients: a collaborative model. Cancer J 2006;12:398-416.

19 Anandarajah G, Hight E. Spirituality and medical practice: using the hope questions as a practical tool for spiritual assessment. Am Fam Physician 2001;63:81-8.

20 Edwards JK. Handbook of Strengths-Based clinical practices. New York: Routledge/Taylor \& Francis Group, 2018.

21 Gottlieb LN. Strenghts-based nursing care. New York: Springer Publishing Co, 2012.

22 Joseph CB. Health and healing for person and family by Laurie N. Gottlieb and Bruce Gottlieb. J Hosp Librariansh 2013;13:301-2.

23 Leget C. Art of living, art of dying: spiritual care for a good death. Jessica Kingsley Publishers, 2017.

24 Weick A, Rapp C, Sullivan WP, et al. A strengths perspective for social work practice. Soc Work 1989;34:350-4.

25 Hughes ME. A strengths perspective on caregiving at the endof-life. Australian Social Work 2015;68:156-68.

26 Wright DK, Gros CP, Pugnaire Gros C. Theory inspired practice for end-of-life cancer care: an exploration of the McGill model of nursing. Can Oncol Nurs J 2012;22:175-81.

27 Pope C, Mays N, Popay J. Synthesizing qualitative and quantitative health evidence: a guide to methods. Buckingham: Open University Press, 2007.

28 Braun V, Clarke V. Using thematic analysis in psychology. Qual Res Psychol 2006;3:77-101.

29 Buckley J, Herth K. Fostering hope in terminally ill patients. Nurs Stand 2004;19:33-41.

30 Harrop E, Noble S, Edwards M, et al. Managing, making sense of and finding meaning in advanced illness: a qualitative exploration of the coping and wellbeing 
experiences of patients with lung cancer. Sociol Health Illn 2017;39:1448-64.

31 Karlsson M, Friberg F, Wallengren C, et al. Meanings of existential uncertainty and certainty for people diagnosed with cancer and receiving palliative treatment: a life-world phenomenological study. BMC Palliat Care 2014;13:28.

32 la Cour K, Johannessen H, Josephsson S. Activity and meaning making in the everyday lives of people with advanced cancer. Palliat Support Care 2009;7:469-79.

33 Nilmanat K, Promnoi C, Phungrassami T, et al. Moving beyond suffering: the experiences of Thai persons with advanced cancer. Cancer Nurs 2015;38:224-31.

34 Rohde G, Kersten C, Vistad I, et al. Spiritual well-being in patients with metastatic colorectal cancer receiving noncurative chemotherapy: a qualitative study. Cancer Nurs 2017;40:209-16.

35 Sand L, Olsson M, Strang P. Coping strategies in the presence of one's own impending death from cancer. J Pain Symptom Manage 2009;37:13-22.

36 Rosenfeld B, Saracino R, Tobias K, et al. Adapting MeaningCentered psychotherapy for the palliative care setting: results of a pilot study. Palliat Med 2017;31:140-6.

37 Breitbart W, Masterson M. Meaning-centered psychotherapy in the oncology and palliative care settings. In: Russo-Netzer P, Schulenberg S, Batthyany A, eds. Clinical perspectives on meaning. Springer, 2016: 245-60.

38 Duggleby W, Cooper D, Nekolaichuk C, et al. The psychosocial experiences of older palliative patients while participating in a living with hope program. Palliat Support Care 2016;14:672-9.

39 McClement SE, Chochinov HM, Hack TF, et al. Dignityconserving care: application of research findings to practice. Int J Palliat Nurs 2004;10:173-9.
40 Xiao H, Kwong E, Pang S, et al. Perceptions of a life review programme among Chinese patients with advanced cancer. $J$ Clin Nurs 2012;21:564-72.

41 Tait GR, Schryer C, McDougall A, et al. Exploring the therapeutic power of narrative at the end of life: a qualitative analysis of narratives emerging in dignity therapy. BMJ Support Palliat Care 2011;1:296-300.

42 Tuck I, Johnson SC, Kuznetsova MI, et al. Sacred healing stories told at the end of life. J Holist Nurs 2012;30:69-80.

43 Olsman E, Leget C, Onwuteaka-Philipsen B, et al. Should palliative care patients' hope be truthful, helpful or valuable? An interpretative synthesis of literature describing healthcare professionals' perspectives on hope of palliative care patients. Palliat Med 2014;28:59-70.

44 Martínez M, Arantzamendi M, Belar A, et al. 'Dignity therapy', a promising intervention in palliative care: a comprehensive systematic literature review. Palliat Med 2017;31:492-509.

45 Keall RM, Clayton JM, Butow PN. Therapeutic life review in palliative care: a systematic review of quantitative evaluations. J Pain Symptom Manage 2015;49:747-61.

46 Guerrero-Torrelles M, Monforte-Royo C, Rodríguez-Prat A, et al. Understanding meaning in life interventions in patients with advanced disease: a systematic review and realist synthesis. Palliat Med 2017;31:798-813.

47 Johnson S. Hope in terminal illness: an evolutionary concept analysis. Int J Palliat Nurs 2007;13:451-9.

48 Park CL. Making sense of the meaning literature: an integrative review of meaning making and its effects on adjustment to stressful life events. Psychol Bull 2010;136:257-301.

49 Block SD. Psychological considerations, growth, and Transcendence at the end of life. JAMA 2001;285:2898-905.

50 Coghlan D. Participatory action research in health care. J Adv Nurs 2007;60:110. 